\title{
Tomographic Images of Klyuchevskoy Volcano P-Wave Velocity
}

\author{
Jonathan M. Lees ${ }^{1}$, Neill Symons ${ }^{2}$, Olga Chubarova ${ }^{3}$, \\ Valentina Gorelchik ${ }^{3,4}$, and Alexei Ozerov ${ }^{3}$
}

Three-dimensional structural images of the P-wave velocity below the edifice of the great Klyuchevskoy group of volcanoes in central Kamchatka are derived via tomographic inversion. The structures show a distinct low velocity feature extending from around $20 \mathrm{~km}$ depth to $35 \mathrm{~km}$ depth, indicating evidence of magma ponding near the Moho discontinuity. The extensive low velocity feature represents, at least to some degree, the source of the large volume of magma currently erupting at the surface near the Klyuchevskoy group.

\section{INTRODUCTION}

Tomographic inversion for three-dimensional compressional wave velocity at volcanoes has been relatively routine since the early 1980's. Examples of three dimensional structure derived from seismic travel time inversion include Mount St. Helens [Lees, 1992], Mount Rainier [Lees and Crosson, 1990; Moran et al., 1999], Kilauea[Ellsworth and Koyangi, 1977; Haslinger et al., 2001; Rowan and Clayton, 1993; Thurber, 1984], Pinatubo [Mori et al., 1996], Etna [Aloisi et al., 2002], Unzen [Ohmi and Lees, 1995], Campei Flegrei [Aster and Meyer, 1988], Medicine Lake [Evans and Zucca, 1988], Vesuvius [De Natale et al., 1998; Zollo et al., 1998], Yellowstone [Benz and Smith, 1984; Clawson et al., 1989; Husen and Smith, 2004; Iyer et al., 1981; Miller and Smith, 1999; Yuan and Dueker, 2005], Mount Spurr, AK, [Brown et al., 2004], Long Valley, CA, [Dawson et al., 1990; Dawson et al., 1987; Hauksson, 1988; O'Doherty et al., 1997; Peppin, 1985; Sanders, 1993; Sanders et al., 1995; Sanders

\footnotetext{
${ }^{1}$ University of North Carolina, Chapel Hill

2 Sandia National Laboratories

${ }^{3}$ Institute for Volcanology and Seismology Far-East Branch of the Russian Academy of Sciences, Petropavlovsk-Kamchatsky

${ }^{4}$ Deceased

Volcanism and Subduction: The Kamchatka Region Geophysical Monograph Series 172

Copyright 2007 by the American Geophysical Union. 10.1029/172GM21
}

et al., 1994], as well as numerous others. In nearly all these cases low velocities were observed below the edifice of the volcanoes and they were interpreted as evidence for magma accumulation, sometimes called the magma plexus [Benz et al., 1996]. In this paper we apply tomographic inversion methods to data collected on a regional network of seismic stations near Klyuchevskoy volcano, Kamchatka, Russia.

Klyuchevskoy volcano is one of the most active volcanoes in the Pacific Rim [Fedotov and Masurenkov, 1991]. Construction of most of the $4800 \mathrm{~m}$ tall edifice occurred over the past 7000 years (Figures 1 and 2). It has erupted numerous times in the recent past and, along with Bezymianny [Gorshkov, 1959] and Tolbachik [Fedotov et al., 1979] volcanoes, represents possibly the most productive volcanic center of all subduction zones. On a larger scale it is important to note that Klyuchevskoy volcano and nearby related volcanic centers lie in the central Kamchatka depression off the axis of the coastal arc. Klyuchevskoy and Sheveluch are the northern most active volcanoes of the Kamchatka arc, which coincides with the collision of the western Aleutians and the Kamchatka Peninsula. Seismic and geochemical analyses have shown that the Klyuchevskoy-Sheveluch axis straddles the northern terminus of the subducting Kamchatka slab [Lees et al., 2007; Yogodzinski et al., 2001]. Furthermore, the subducting slab shallows noticeably at its northern terminus [Lees et al., 2007]. According to current models, warm mantle material erodes the slab as it is pressed around the unconstrained slab edge, causing magmas north of Klyuchevskoy 


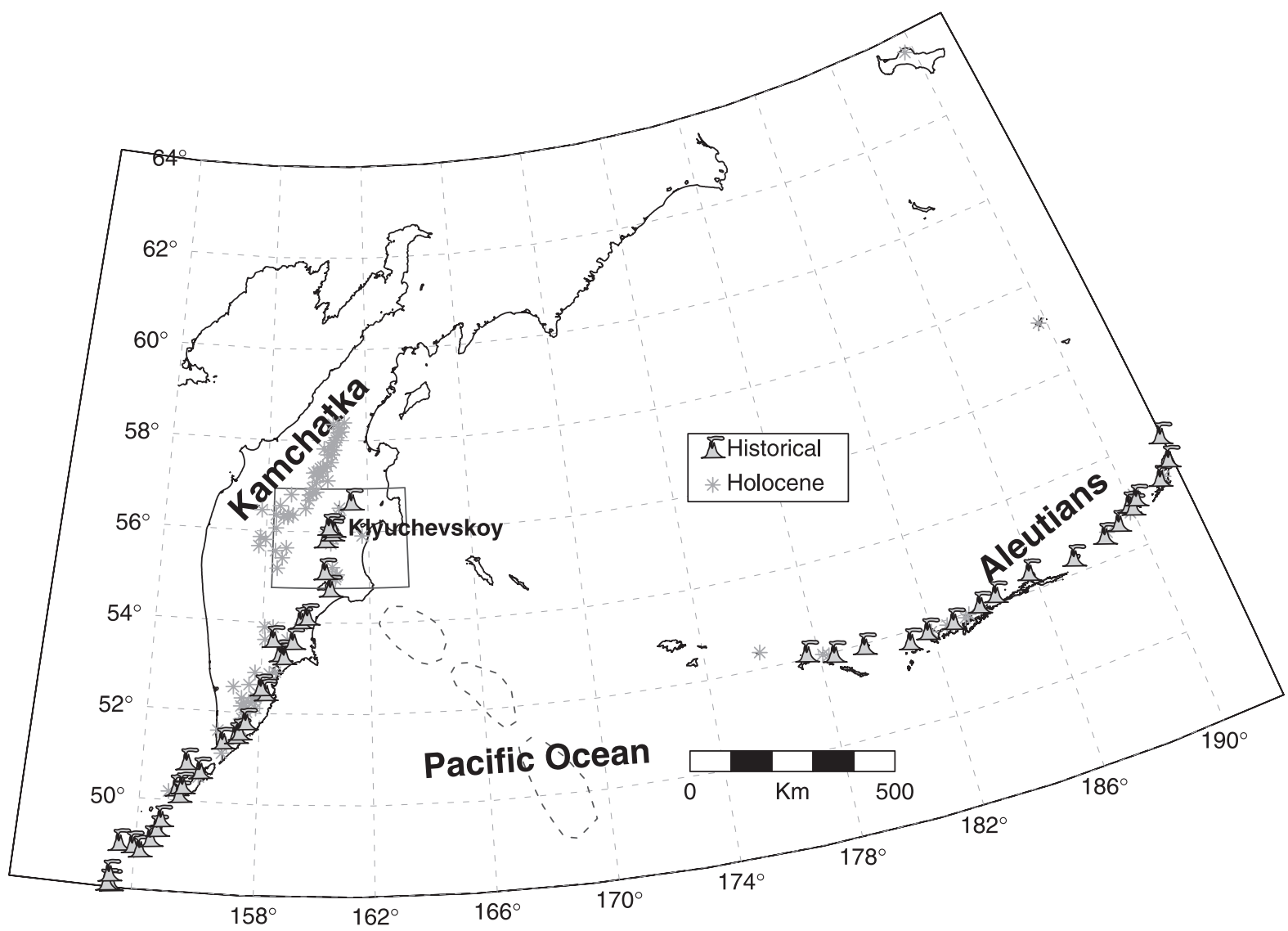

Figure 1. Map of the Kamchatka-Aleutian subduction zones showing the relationship of the target region of this study to volcanism on the subducting Pacific Plate. The Aleutians terminate near Kamchatka where the Bering Island represents the last land masses situated over the Bering faults. The target region for the tomographic inversion is the rectangular patch including the Klyuchevskoy group, extending from Kizimen in the south to Sheveluch in the north. The bounds of the tomographic inversion are limited by the station array and local earthquake event catalogue available for travel time inversion. Active arc volcanoes are represented by larger triangles and smaller ones are inactive

to have distinct geochemical signatures associated with slab melt [Yogodzinski et al., 2001].

Given the large flux of magma at the surface of the Klyuchevskoy group (about 0.17 cubic $\mathrm{km} / \mathrm{year}$, ) we expect to see a large accumulation of magma stored in the crust or upper mantle. Active source seismic data acquired along the coast of Kamchatka have been used in the past to suggest that there is nearly no signature of a large magma body immediately below Klyuchevskoy, although a small accumulation was postulated below Bezymianny Volcano [Anosov et al., 1978; Utnasin et al., 1976]. Petrologic and geochemical analysis of Klyuchevskoy volcanic material suggests that the Klyuchevskoy group has a typical calc-alkaline composition [Kersting and Arculus, 1995; Ozerov, 2000]. Ozerov et al. [1997] conclude that magma genesis at Klyuchevskoy occura between $150-60 \mathrm{~km}$ depth where high-magnesium basalts are formed. They further suggest that there is no evidence for significant magma accumulation above $20 \mathrm{~km}$ depth and that at least two narrow, separate conduit systems feed into the active Bezymianny and Klyuchevskoy volcanoes. In the 20-30 km range they infer the presence of two distinct diverging conduits where fractionation occurs. The model suggests that the physical divergence ultimately produces the geochemical differentiation observed in the surface products: most Klyuchevskoy magmas are basaltic, whereas those at Bezymianny are andesitic-dacitic. A large concentration of hypocenters is evident in this zone indicating either tectonic or magmatic activity at $20-30 \mathrm{~km}$ depth, although the patterns of seismicity do not show explicitly the diverging conduits proposed by Ozerov et al.[1997].

\section{DATA}

Data used in this study consisted of over 1444 well-located events extracted from the extensive catalogue in PetropavlovskKamchatsky [Gorelchik et al., 1990]. Data ranged from 1981- 
1994 and were obtained from the KEMSD (Kamchatkan Experimental Methodological Seismological Department) and the IVGG (Institute of Volcanic Geology and Geochemistry). Events were recorded on paper records and picked by hand by the authors. $\mathrm{P}$ and $\mathrm{S}$ wave arrival times were determined at the observatory in Petropavlovsk and estimated errors were typically between .05 and $.15 \mathrm{~s}$. Hypocenters were located initially using a standard one-dimensional velocity model derived for the Klyuchevskoy region. Events were chosen only if they were well recorded at more than 5 stations and were deemed of high quality by the observers who performed the manual arrival time estimations. Typically, these earthquakes had root mean square residuals of $0.48 \mathrm{~s}$ (standard deviation $0.2 \mathrm{~s}$ ), a median lateral location error of $1.5 \mathrm{~km}$ and a median gap of 124 degrees. (The large gap is due to the sparse network in operation during the 1980's and 1990's). Travel time arrivals (6461 P-wave and 9115 S-wave) were extracted, filtered for outlier high fluctuations and the data set was inverted for P-wave velocity.

\section{INVERSION METHODOLOGY}

The methods used in this study follow that of Symons and Crosson[1997]. It is based on finite difference calculations of travel times for forward modeling similar to that developed by Benz [1982]. The target region is divided into blocks 5 $\mathrm{km}$ to a side, varying in depth according to divisions of the layered model used for simple 1-dimensional event locations. Travel times are calculated using a finite difference method [Hole, 1992; Vidale, 1988] which provides a solution to the

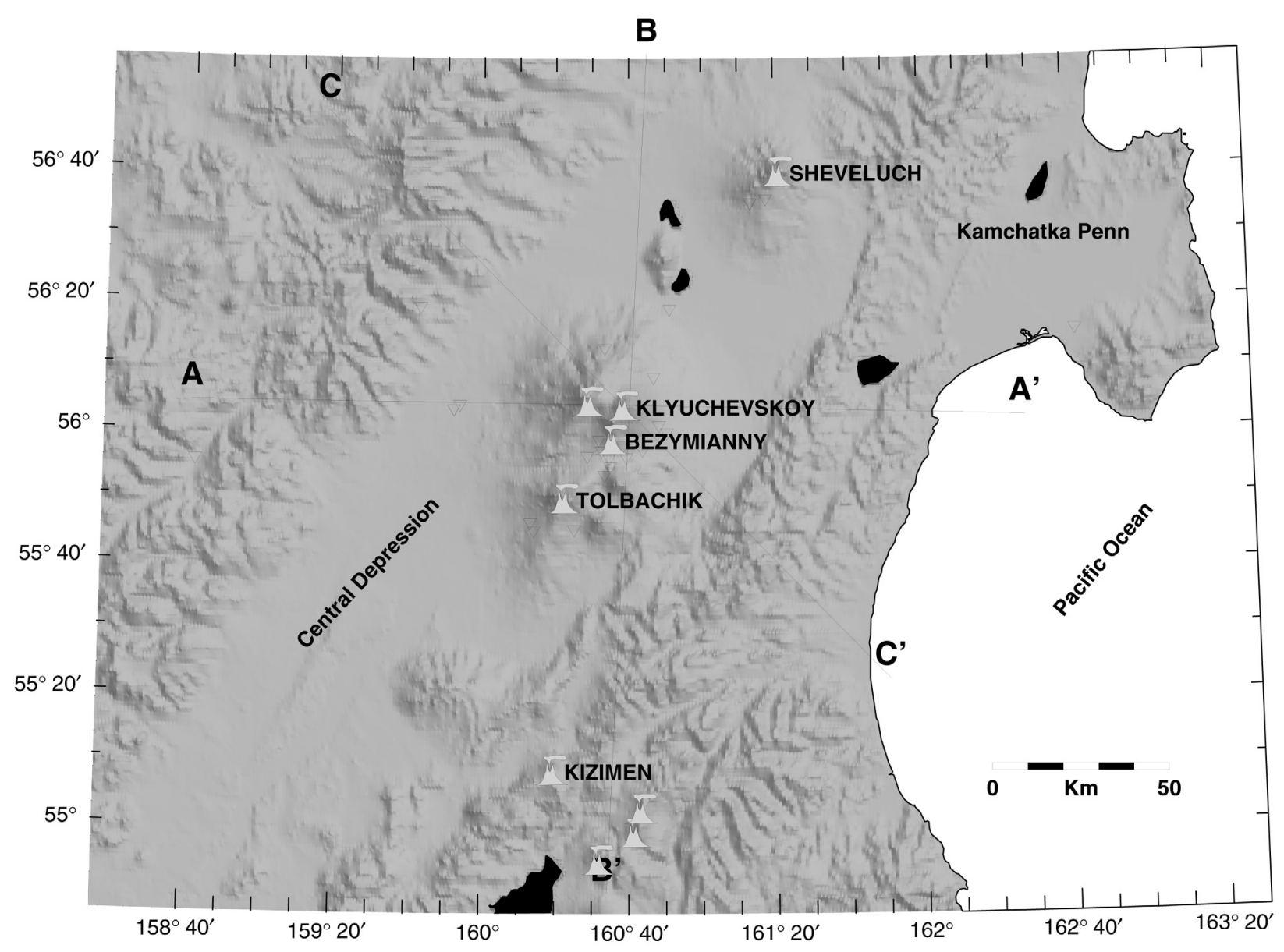

Figure 2. Detailed topographic map of the target region inverted in this study. The Klyuchevskoy group is near the center of the inversion target region. Cross sections are plotted for later reference to vertical slices through the velocity perturbation results. The deep graben running from southwest to northeast through the target region is known as the central Kamchatka depression. The Klyuchevskoy group is located within the Central Kamchatka depression, in contrast to the more southerly volcanoes of the Kamchatka arc that form a volcanic clear front along the Kamchatka trench. Red triangles are volcanoes and black inverted triangles are station locations. 
eikonal equation at nodes of a 3-D grid. Continuous traveltime is then constructed by tri-linear interpolation.

The target region is defined as a vector $(\mathbf{m})$ of the $p$ slowness ( 1 /velocity) values at every node in a three-dimensional grid plus four hypocenter coordinates for each of $q$ earthquakes used in the inversion. Since inversion of seismic travel times is inherently non-linear, the approach is to solve a series of linear inversions. Linearizing the travel-time about a reference model and writing the residual (observed minus calculated travel-time) of the $i$-th earthquake at the $j$-th receiver as

$$
r_{i j}=\sum_{k=1}^{p+4 q} \frac{\partial T_{i j}}{\partial m_{k}} \delta m_{k}
$$

we have, in matrix form

$$
\mathbf{J} \delta \mathbf{m}=\mathbf{r}
$$

where $\mathbf{J}$ is the partial derivative matrix and $\delta \mathbf{m}$ is the correction required to make the reference model fit the data.

In general, equation (2) will be inconsistent and under-constrained, and $\left(\mathbf{J}^{\mathrm{T}} \mathbf{J}\right)^{-1}$ will not necessarily exist. We regularize the problem by augmenting the system with additional constraint equations to penalize departure of the final model from a priori assumptions. For example, the Laplacian operator has been widely used as a smoothing operator in inversion studies [Constable et al., 1987; Lees, 1992]. This constraint forces models to be smooth by requiring gradients to be small.

Since we are interested in finding a smooth final model that is consistent with the observations (rather than just finding smooth perturbations) we modify the constraint equations as follows. If $\mathbf{L}$ is the discrete Laplacian operator that acts only on the slowness nodes of our solution vector $\mathbf{m}$, then $\mathbf{b}_{0}=\mathbf{L} \mathbf{m}_{0}$ is the roughness of the current model $\mathbf{m}_{0}$. Since $\mathbf{m}=\mathbf{m}_{0}+\delta \mathbf{m}$, roughness will be minimized in the final model, $\mathbf{m}$, if

$$
\mathbf{b}_{\mathbf{0}}+\mathbf{L} \delta \mathbf{m}=\mathbf{0}
$$

A weighted version of this equation is added as a constraint to Equation (2) and solved by least squares. Since the combined system of equations is sparse (on the order of $0.001 \%$ non-zero elements) we use an iterative conjugate gradient method [Paige and Saunders, 1982] to simultaneously solve the entire problem in a least-squares sense for all slowness and hypocenter parameters.

Equation (1) is only a linearization of the true problem so we require multiple iterations to find a final solution. Iteration is continued until the norm of the solution vector $\delta \mathbf{m}$ reaches some prescribed low level. In practice the system typically converges in fewer than ten iterations.
An illustration of the sensitivity of the inversion method is presented in Plate 1. (Please see the "Animated view of the tomographic inversion of subsurface of Kliuchevskoi volcano" on the CDROM accompanying this volume.) Point spread functions are used to estimate the resolving power of the inversion. These represent the response of the inversion methods to a model that has a $7 \mathrm{~km}$ diameter perturbation located at points of interest in the model. Tests show that the derived perturbations in the zone of interest (below Klyuchevskoy complex) are well-resolved (to within $7 \mathrm{~km}$, or 1.5 block radius) with data used in this study. We are thus confident that the larger anomalies derived from these data represent real structures and do not reflect spurious noise or other adverse affects. At the edges of the models where ray coverage is limited, on the other hand, the inversion results are not conclusive and we refrain from interpretation. The interpretations described below take a conservative stance and are thus restricted to regions that have a good resolution and low standard error. Anomalies that extend beyond a typical 2-3 block radius are considered to be well resolved and open to interpretation with confidence.

\section{RESULTS}

The P-wave velocity anomalies show considerable heterogeneity near the surface with fluctuating high and low perturbations (Plates 2 and 3). The first anomalous regions appear between Klyuchevskoy and Sheveluch as high velocity perturbations at depths of 5-7 km. The high and low velocity anomalies are very heterogeneous (alternating between high and low) between 9 and $13 \mathrm{~km}$ depth. An apparent high velocity ridge or lineation is evident along an axis from Klyuchevskoy and Sheveluch and 50-80 km diameters high velocity is evident north east of Kizimen volcano. From $13-20 \mathrm{~km}$ a broad lower velocity anomaly is observed in abroad region between Klyuchevskoy and Sheveluch. This region has a lateral extent of more than 100 $\mathrm{km}$. Around $21-23 \mathrm{~km}$ depth there is a broad higher velocity anomaly that extends over the whole model. Beginning at $23 \mathrm{~km}$ depth a concentrated, nearly circular, low velocity anomaly is clearly defined below the Klyuchevskoy complex. It has a radius of about $12 \mathrm{~km}$ and is offset from the peak of Klyuchevskoy by $10 \mathrm{~km}$. This low velocity anomaly extends to depths of 35-37 km, although loss of resolution at these depths prevents us from providing clear delineation of the anomaly much below $33-35 \mathrm{~km}$ depth. To illustrate the degree of this perturbation, the low velocities at $25-27 \mathrm{~km}$ depth range from 5.3 to 4.5 in the center of the anomalous region. The standard 1-D velocity model used for this region at these depths is typically $6.8-7.7 \mathrm{~km}$ depth. Assuming a background velocity of $7.34 \mathrm{~km} / \mathrm{s}$ the estimates from our 3-D 
LEES ET AL. 297
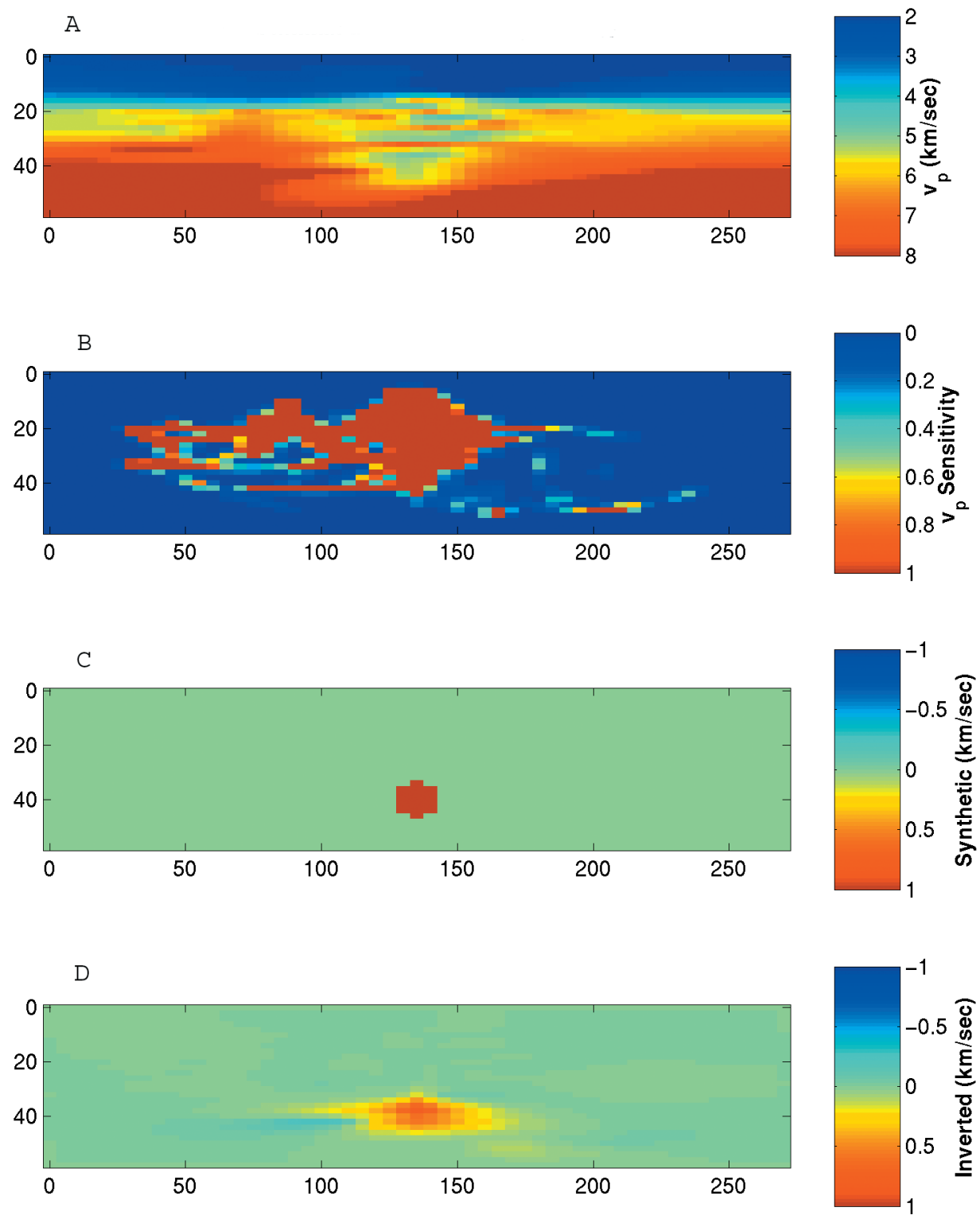

Plate 1. Cross section and point spread function of tomographic inversion. A) Cross section through the tomographic model. B) Sensitivity estimates of the inversion through the cross section in (A). C) Spike inserted in model at depth of $20 \mathrm{~km}$. D) Result of inversion of spike. Note that the synthetic blob is relatively well resolved at $20 \mathrm{~km}$ depth. 

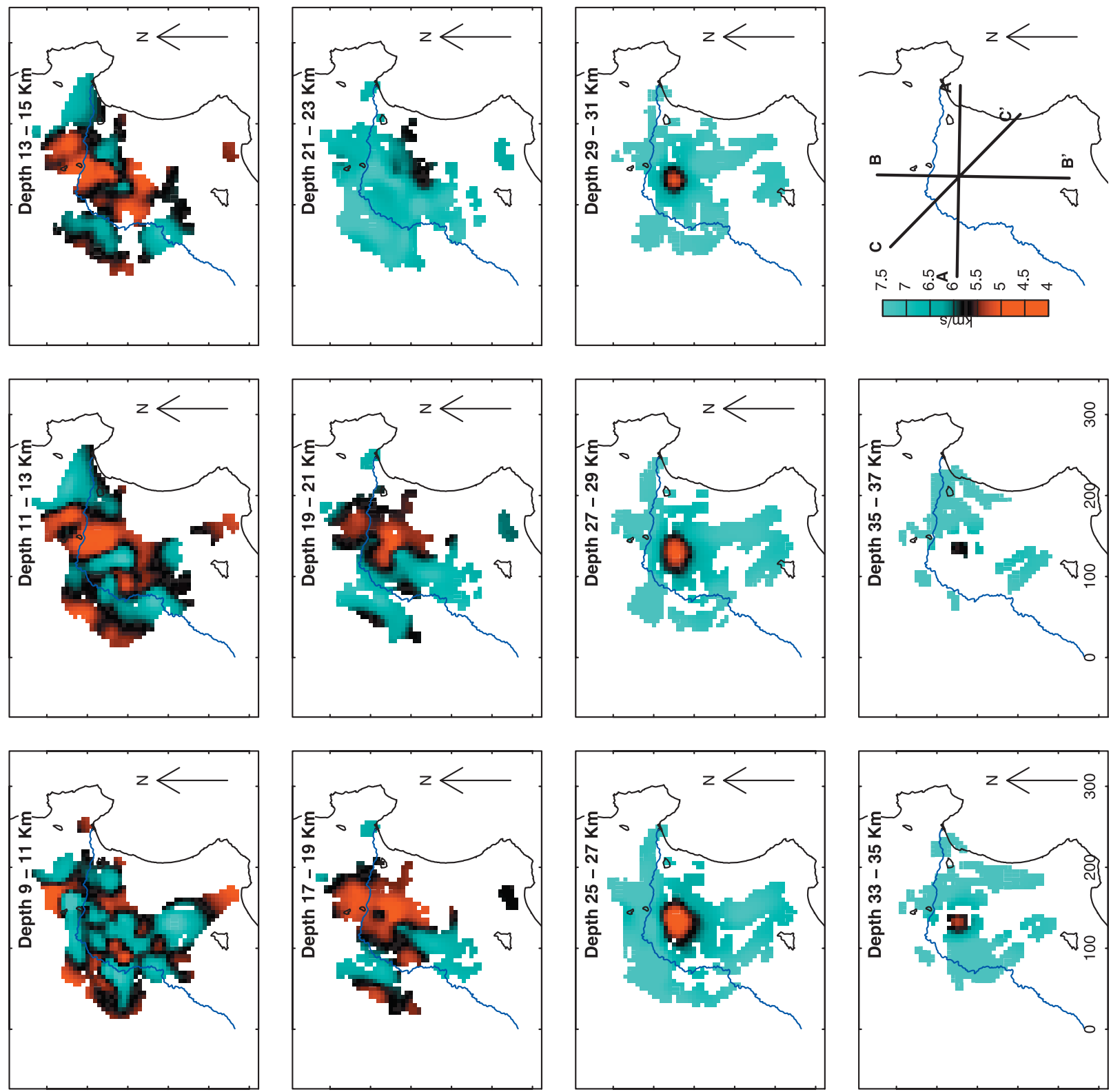

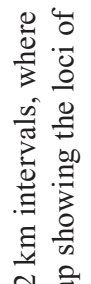

సै छิ

㺃

$\stackrel{0}{ \pm}$

总

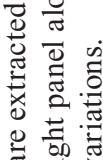

흘

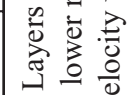

-

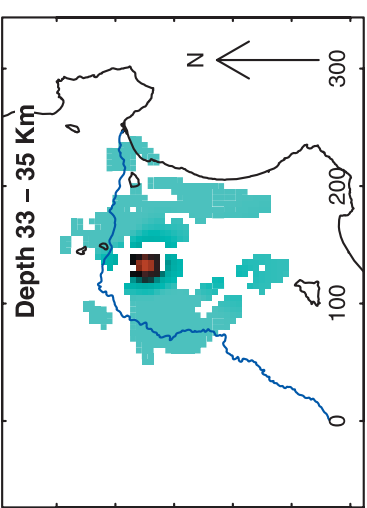

흘

党忿

.

छ छ

至证

ब $\begin{aligned} & 1 \\ & 0 \\ & 0\end{aligned}$

.류

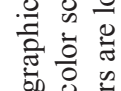

可

过
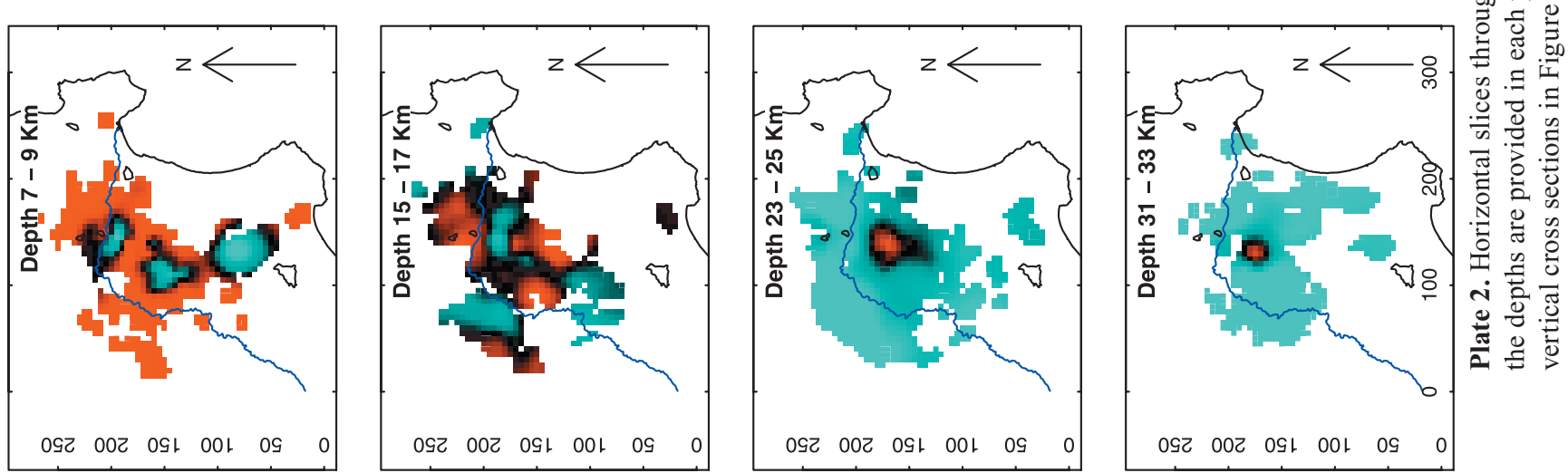

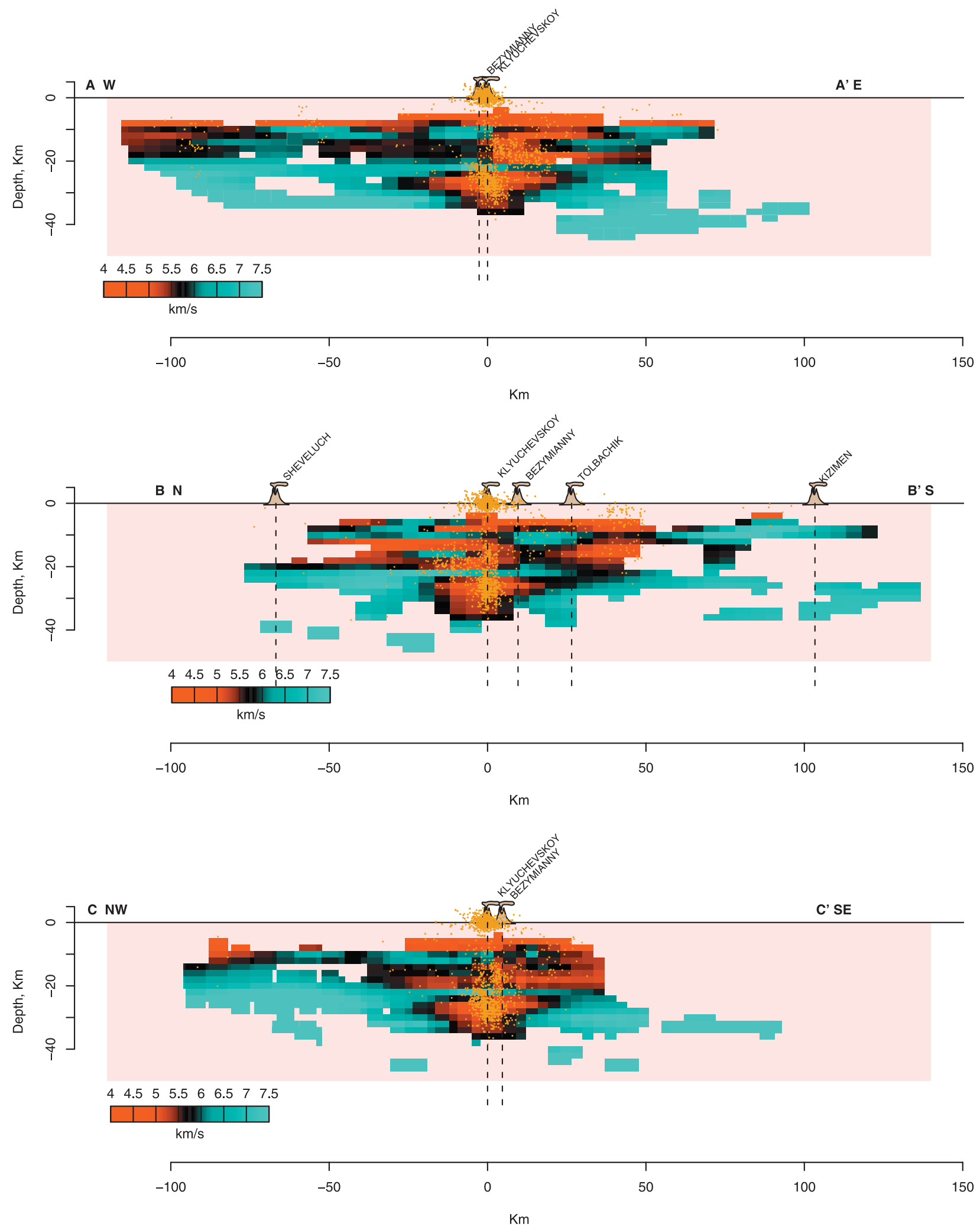

Plate 3. Inversion results for Klyuchevskoy group, vertical cross sections. These sections correspond to the map diagram in Figure 2 and the lower left panel of Figure 4. Red regions represent low velocity, blue high velocity. Yellow points are locations of local earthquakes used in this study, projected from a $20 \mathrm{~km}$ swath about the line of cross section. Note the correlation of hypocenters to the low velocity accumulations at depth. 
model suggest perturbations ranging from $27-38 \%$. Even if these values are over-estimated, they represent a significant perturbation at these depths. The low velocity anomaly at 23-35 km depth coincides with the concentration of deep seismicity below the Klyuchevskoy volcanic complex.

The distribution of high and low velocity anomalies is particularly evident when viewed in cross section (Plate 3 ). The low velocity anomaly situated below the Klyuchevskoy group has a cylindrical or conical shape tapering down towards the Moho (23-35 km depth). A higher velocity sill or layer is above this and in the shallower regions, above $12 \mathrm{~km}$ depth, numerous heterogeneous anomalies are distributed throughout the cross sections. Although velocity perturbations can be attributed to a variety of sources, we assume that the shallow regions in this part of Kamchatka are related to the complex structures accumulated over the course of subduction and accretion of the Kamchatka arc. Shallow anomalies may be associated with lithologic variations, hydrothermal alteration, and distribution of faults and cracks, in addition to geothermal fluctuations. Without additional a priori information constraining the interpretation of these complex variations it is difficult to assign a specific interpretation to a particular anomaly on an individual basis.

In the case of the deeper anomaly (21-35 km depth) below the edifice we are confident that the velocity variation is most likely due to the presence of a significant amount of partial melt or, alternatively, an intense thermal anomaly. The deep anomaly furthermore coincides with deep long period events similar to those found below Mt. Fuji [Nakamichi et al., 2004]. Measurements of seismic P-wave velocities for igneous rocks in laboratory environments suggest that perturbations greater than $50 \%$ indicate a considerable proportion of partial melt in samples [Sato et al., 1989]. It is rare to find tomographic inversions with perturbations of this magnitude, although some exceptions are notable [Horiuchi et al., 1997]. This is partially due to issues related to regularization introduced in the calculations because of inconsistencies in the data [Lees, 2007]. It may, however, be due to the fact that large accumulations of melt or partial melt, on batholithic spatial scales at least, are simply not present in the deeper parts of the crust [Coleman et al., 2004; Glazner et al., 2004]. On the other hand, it may be that significant percentages of partial melt exist but are distributed in a way that is masked and invisible to tomographic analysis. The non-uniqueness of the tomographic inversion, coupled with the lack of additional constraining information (such as thermal history, density, or lithology derived from xenoliths, for example) makes it impossible to determine unequivocally the exact perturbation magnitude associated with images derived via seismic inversion.

While it is clear that a significant velocity anomaly is present below Klyuchevskoy (Plate 3), the resolving power of the data is not sufficient to delineate individual structures internal to anomalies discussed here. The $25 \%$ perturbation suggests there is a significant heat anomaly at $20-30 \mathrm{~km}$ depth and it is likely that there is a substantial amount of melt accumulated in this zone. The resolving capabilities of this data set are not fine enough to allow for the isolation of individual conduits connected to specific active volcanic centers like Klyuchevskoy, Bezymianny or Tolbachik. Rather, we see a broad subsurface region with low enough velocity to suggest that significant melt is present and most likely provides a magma storage region that feeds these volcanic centers. The images produced in this study fall into an intermediate scale for tomographic investigation below volcanic regions. At smaller scales, shallow anomalies interpreted as magma accumulation have been observed above $10 \mathrm{~km}$ [Lees, 1992]. At larger scales, anomalous low velocities are observed in the upper mantle below calderas like Yellowstone[Clawson et al., 1989] and Long Valley[Sanders et al., 1995]. At the caldera scale, amplitudes of anomalous features, compared to expected melt accumulates anticipated for such large scale eruptions, are relatively small. Furthermore, large amplitude, extensive low velocities are often absent in mid-ocean ridge spreading centers where it is known that a considerable flux of volcanic material emerges along axes. The position and amplitude of the anomalies below Klyuchevskoy, on the other hand, provide strong evidence for significant melt accumulations and support the idea that lower crustal storage is probably present at the northern terminus of the Kamchatka arc.

It has been noted that the northern terminus of the Kamchatka arc represents the northern terminus of subducting Pacific plate where the plate apparently exposes an edge as it plunges into the mantle [Lees, 2006; Levin et al., 2002; Park et al., 2002; Yogodzinski et al., 2001]. Yogodzinski et al. [2001] showed that adakitic material, derived from slab contamination of the upper mantle, is present at Sheveluch but not at Klyuchevskoy. The lack of significant slab material north of the Klyuchevskoy group allows the slab to bow upward below Klyuchevskoy where the plate is deformed by shoaling. The results of this study do not shed new light on this process, although it may be that shoaling slab creates a state of buoyancy that encourages a large flux of magma. The slab window created by the opening of the Pacific slab north of Kamchatka (below the Bering Islands) provides an upper mantle thermal conduit that may accentuate magmatism in this subduction zone [Lees et al., 2007].

Active source seismic investigations of the Klyuchevskoy region indicated low attenuation of seismic waves at shallow depths below Klyuchevskoy, although the authors report a corresponding shadow zone below Bezymianny[Anosov et al., 1978]. The absence of a significant attenuating body below Klyuchevskoy precluded the possibility of a large magma body below the edifice, although a small low velocity 
region was postulated for Bezymianny. Anosov et al. [1978] recognized that there must be a deeper source of magma at depth and hypothesized magma accumulation below $20 \mathrm{~km}$. Images presented here delineate the deep magma accumulation, although we cannot draw conclusions here, due to resolution limitations, about the presence or absence of magma accumulations below Klyuchevskoy or Bezymianny.

\section{CONCLUSION}

Tomographic P-wave images of Klyuchevskoy volcano show a significant $\mathrm{P}$-wave anomaly ranging from $20-40 \mathrm{~km}$ below the edifice of the Klyuchevskoy group. This anomaly appears narrow in the $20 \mathrm{~km}$ depth range and broadens laterally around $30-35 \mathrm{~km}$ depth, perhaps suggesting ponding and accumulation at the Moho discontinuity. We cannot yet determine the level of percent melt in this region, although the size of the anomaly strongly suggests that a significant amount of magma resides at depth below the Klyuchevskoy group and is most likely the main source feeding this very active region along the Kamchatka Subduction zone.

Acknowledgements. Support for this work was provided in part by grants NSF EAR 0337462 and NSF EAR-0440054. The authors are grateful to Seth Moran for helpful comments.

\section{REFERENCES}

Aloisi, M., O. Cocina, G. Neri, B. Orecchio, and E. Privitera, Seismic tomography of the crust underneath the Etna Volcano, Sicily, Phys. Earth Planet. Int., 134 (3-4), 139-155, 2002.

Anosov, G. I., S. K. Bikkenina, and A. A. Popov, Glubinnoe seismicheskoe zondirovanie Kamchatki: Deep seismic sounding of Kamchatka (in Russian), 129 pp., Nauka, Moscow, 1978.

Aster, R. C., and R. P. Meyer, Three-dimensional velocity structure and hypocenter distribution in the Campi Flegrei caldera, Italy, Tectonophysics, 149, 195-218, 1988.

Benz, H., B. A. Chouet, P.B. Dawson, J. C. Lahr, R. A. Page, and J. A. Hole, Three-dimensional $\mathrm{P}$ and $\mathrm{S}$-wave velocity structure of Redoubt Volcano, Alaska, J. Geophys. Res., 101 (4), 8111-8128, 1996.

Benz, H. M., Simultaneous inversion for lateral velocity variations and hypocenters in the Yellowstone region using earthquake and refraction data, University of Utah, 1982.

Benz, H. M., and R. B. Smith, Simultaneous inversion for lateral velocity variations and hypocenters in the Yellowstone region using earthquake and refraction data, JGR. Journal of Geophysical Research. B, 89 (2), 1208-1220, 1984.

Brown, J., S.G. Prejean, H. Zhang, and J. Power, Double difference earthquake relocation and tomography at Mount Spurr Volcano, Alaska, 1991 to 2004, Eos, Transactions, American Geophysical Union, 85 (47), S51A-0140, 2004.

Clawson, S.R., R.B. Smith, and H.M. Benz, P wave attenuation of the Yellowstone Caldera from three-dimensional inversion of spectral decay using explosion source seismic data, J. Geophys. Res., 94 (6), 7205-7222, 1989 .

Coleman, D.S., W. Gray, and A.F. Glazner, Rethinking the emplacement and evolution of zoned plutons; geochronologic evidence for incremental assembly of the Tuolumne Intrusive Suite, California, Geology, 32 (5), 433-436, 2004.

Constable, A.C., R.L. Parker, and C.G. Constable, Occam's inversion: A practical algorithm for generating smooth models from electromagnetic sounding data, Geophysics, 52 (3), 289-300, 1987.

Dawson, P.B., J.R. Evans, and H.M. Iyer, Teleseismic tomography of the compressional wave velocity structure beneath the long Valley region, California, J. Geophys. Res., 95 (B7), 11021-11050, 1990.

Dawson, P.B., H.M. Iyer, J.R. Evans, and U. Achauer, Inversion of teleseismic travel time residuals to investigate the three-dimensional P-velocity structure of the crust and upper mantle, the Long Valley, California, region, International Union of Geodesy and Geophysics, General Assembly, 19 (1), 55, 1987.

De Natale, G., P. Capuano, C. Troise, and A. Zollo, Seismicity at Somma-Vesuvius and its implications for the 3D tomography of the volcano, in J. Volc. Geoth. Res., edited by F.J. Spera, B. de Vivo, R.A. Ayuso, and H.E. Belkin, pp. 175-197, 1998.

Ellsworth, W.L., and R.Y. Koyangi, Three-dimensional crust and mantle structure of Kilauea Volcano, Hawaii, J.Geophys. Res., 82 (33), 5379-5394, 1977.

Evans, J.R., and J.J. Zucca, Active high-resolution seismic tomography of compressional wave velocity and attenuation structure at Medicine Lake volcano, northern California Cascade Range, J. Geophys. Res., 93, 15016-15036, 1988.

Fedotov, S.A., S.T. Balesta, V.I. Gorelchik, G.B. Flerov, and V.B. Enman, The 1975-1976 strong fissure eruption of the Tolbachik Volcano, Kamchatka, Abstracts of Papers-Pacific Science Congress, 14, 90-91, 1979.

Fedotov, S.A., and Y.P. Masurenkov, Active Volcanoes of Kamchatka, pp. 302, Nauka, Moscow, 1991.

Glazner, A.F., J.M. Bartley, D.S. Coleman, W. Gray, and R.Z. Taylor, Are plutons assembled over millions of years by amalgamation from small magma chambers?, GSA Today, 14 (April/May), 4-11, 2004.

Gorelchik, V.I., O.S. Chubarova, and V.T. Garbuzova, Seismicity of the region of the Northern group of volcanoes in Kamchatka, 1971-1983, Volcanology and Seismology, 10 (N3), 141-157, 1990.

Gorshkov, G.S., Gigantic eruption of the volcano Bezymianny, Bull. Volcanol., 20, 77-109, 1959.

Haslinger, F., C.H. Thurber, M. Mandernach, and P.G. Okubo, Tomographic image of P-velocity structure beneath Kilauea's East Rift Zone and South Flank; seismic evidence for a deep magma body, Geophys. Res. Lett., 28 (2), 375-378, 2001.

Hauksson, E., Absence of evidence for a shallow magma chamber beneath Long Valley Caldera, California, in downhole and surface seismograms, J. Geophys. Res., 93 (11), 13,251-13,264, 1988.

Hole, J.A., Nonlinear high-resolution three-dimensional seismic travel time tomography, Geophys. J. Int., 97, 6553-6562, 1992.

Horiuchi, S., N. Tsumura, and A. Hasegawa, Mapping of a magma reservoir beneath Nikko-Shirane volcano in northern Kanto, Japan, from travel time and seismogram shape anomalies, J. Geophys. Res., 102 (B8), 18071-18090, 1997. 
Husen, S., and R.B. Smith, Probabilistic earthquake resolution in three-dimensional velocity models for the Yellowstone National Park region, Wyoming, Bull. Seismol. Soc. Am., 94 (3), 880-896, 2004.

Iyer, H.M., J.R. Evans, G. Zandt, R.M. Stewart, J.M. Coakley, and J.N. Roloff, A deep low-velocity body under the Yellowstone caldera, Wyoming: Delineation using teleseismic P-wave residuals and tectonic interpretation, Geol. Soc. Am. Bull., 92 (Part I), 792-798, 1981

Kersting, A.B., and R.J. Arculus, Pb isotope composition of Klyuchevskoy Volcano, Kamchatka and North Pacific sediments; implications for magma genesis and crustal recycling in the Kamchatkan arc, Earth Planet. Sci. Letts., 136 (3-4), 133-148, 1995.

Lees, J.M., The magma system of Mount St. Helens: Non-linear high resolution P-wave tomography, J. Volc. Geoth. Res., 53 (1-4), 103-116, 1992.

Lees, J.M., Tomography Of Crustal Magma Bodies, in Cities on Volcanoes, Quito, Ecuador, 2006.

Lees, J.M., Tomography of Crustal Magma Bodies: Implications For Magmatic Systems, in J. Volc. Geoth. Res., pp. in Review, 2007.

Lees, J.M., and R.S. Crosson, Tomographic imaging of local earthquake delay times for 3-D velocity variation in western Washington, J. Geophys. Res., 95 (B4), 4763-4776, 1990.

Lees, J.M., J. VanDecar, E. Gordeev, A. Ozerov, M. Brandon, J. Park, and V. Levin, Three Dimensional Images of the Kamchatka-Pacific Plate Cusp, in Volcanism and Tectonics of the Kamchatka Peninsula and Adjacent Arcs, edited by J. Eichelberger, J.M. Lees, P. Izbekov, and E. Gordeev, pp. in press, 2007.

Levin, V., N. Shapiro, J. Park, and M. Ritzwoller, Seismic evidence for catastrophic slab loss beneath Kamchatka, Nature, 418, 763-767, 2002.

Miller, D.S., and R.B. Smith, P and S velocity structure of the Yellowstone volcanic field from local earthquake and controlled-source tomography, J. Geophys. Res., 104 (7), 15,105-15,121, 1999.

Moran, S.C., J.M. Lees, and S.D. Malone, P-wave velocity structure in the greater Mount Rainier area from local earthquake tomography, J. Geophys. Res., 104 (10), 10,775-10,786, 1999.

Mori, J.J., D. Eberhart-Phillips, and D.H. Harlow, Three-dimensional velocity structure at Mount Pinatubo; resolving magma bodies and earthquake hypocenters, in Fire and mud; eruptions and lahars of Mount Pinatubo, Philippines, edited by C.G.e. Newhall and R.S.e. Punongbayan, pp. 371-382, 1996.

Nakamichi, H., M. Ukawa, and S.i. Sakai, Precise hypocenter locations of midcrustal low-frequency earthquakes beneath Mt. Fuji, Japan, Earth, Planets and Space, 56 (12), e37-e40, 2004.

O’Doherty, K.B., C.J. Bean, and J. McCloskey, Coda wave imaging of the Long Valley Caldera using a spatial stacking technique, Geophys. Res. Lett., 24 (13), 1547-1550, 1997.

Ohmi, S., and J.M. Lees, Three-dimensional P and S-wave velocity structure below Unzen Volcano, J. Volc. Geoth. Res., 65, 1-26, 1995.

Ozerov, A.Y., The evolution of high-alumina basalts of the Klyuchevskoy Volcano, Kamchatka, Russia, based on microprobe analyses of mineral inclusions, J. Volc. Geoth. Res., 95, 65-79, 2000.

Ozerov, A.Y., A.A. Ariskin, F. Kayl, G.Y. Bogoyavlenskaya, and S.F. Karpenko, Petrological-geochemical model for genetic relationships between basaltic and andesitic magmatism of Klyuchevskoy and Bezymyannyy volcanoes, Kamchatka, Petrology, 5 (6), 614-635, 1997.

Paige, C.C., and M.A. Saunders, LSQR: An algorithm for sparse linear equations and sparse least squares, Trans. Math. Software, 8, 43-71, 1982.

Park, J., V. Levin, M.T. Brandon, J.M. Lees, V. Peyton, E. Gordeev, and A. Ozerov, A dangling slab, amplified arc volcanism, mantle flow and seismic anisotropy near the Kamchatka plate corner, in Plate Boundary Zones, edited by S. Stein and J. Freymueller, pp. 295-324, AGU, Washington DC, 2002.

Peppin, W.A., New evidence for magma bodies south of Long Valley Caldera, Mammoth Lakes, California, Eos, Transactions, American Geophysical Union, 66 (46), 959, 1985.

Rowan, L.R., and R.W. Clayton, The three-dimensional structure of Kilauea Volcano, Hawaii, from travel time tomography, $J$. Geophys. Res., 98 (3), 4355-4375, 1993.

Sanders, C.O., Reanalysis of S-to-P amplitude ratios for gross attenuation structure, Long Valley Caldera, California, J. Geophys. Res., 98 (12), 22,069-22,079, 1993.

Sanders, C.O., S.C. Ponko, L.D. Nixon, and E.A. Schwartz, Seismological evidence for magmatic and hydrothermal structure in Long Valley caldera from local earthquake attenuation and velocity tomography, J. Geophys. Res., 100 (5), 8311-8326, 1995

Sanders, C.O., S.C. Ponko, L.D. Nixon, E.A. Schwartz, and Anonymous, Local earthquake attenuation and velocity tomography for magmatic and hydrothermal structure in Long Valley Caldera, California, in Seismol. Res. Lett., pp. 56, 1994.

Sato, H., I.S. Sacks, and T. Murase, The use of laboratory velocity data for estimating temperature and partial melt fraction in the low velocity zone: Comparison with heat flow and electrical conductivity studies, J. Geophys. Res., 94, 5689-5704, 1989.

Symons, N.P., and R.S. Crosson, Seismic Velocity Structure of the Puget Sound Region from 3-D Non-linear Tomography, Geophys. Res. Lett., 21, 2593-2596, 1997.

Thurber, C.H., Seismic detection of the summit magma complex of Kilauea volcano, Hawaii, Science, 233, 165-167, 1984.

Utnasin, V.K., A.I. Abdurakhmanov, G.I. Anosov, Y.A. Budyansky, V.I. Fedorchenko, Y.K. Markhinin, and S.T. Balesta, Types of magma foci of island arc volcanoes and their study by the method of deep seismic sounding of Kamchatka, in Volcanoes and Tectosphere, pp. 123-137, Tokai University Press, 1976.

Vidale, J.E., Finite-difference traveltime calculation, Bull. Seis. Soc. Am., 78, 2062-2076, 1988.

Yogodzinski, G.M., J.M. Lees, T.G. Churikova, F. Dorendorf, G. Woerner, and O.N. Volynets, Geochemical evidence for the melting of subducting oceanic lithosphere at plate edges, Nature, 409, 500-504, 2001.

Yuan, H., and K. Dueker, Teleseismic P-wave tomogram of the Yellowstone plume, Geophys. Res. Lett., 32, no.7, 4, 2005.

Zollo, A., P. Gasparini, J. Virieux, G. Biella, E. Boschi, P. Capuano, R. de Franco, P. Dell'Aversana, R. de Matteis, G. De Natale, G. Iannaccone, I. Guerra, H. Le Meur, and L. Mirabile, An image of Mt. Vesuvius obtained by 2D seismic tomography, in J. Volc. Geoth. Res., edited by F.J. Spera, B. de Vivo, R.A. Ayuso, and H.E. Belkin, pp. 161-173, 1998. 